\title{
Nevus Araneus
}

National Cancer Institute

\section{Source}

National Cancer Institute. Nevus Araneus. NCI Thesaurus. Code C3481.

A type of telangiectasia comprising a central red spot with red, radiating extensions. 